Supporting Information

\title{
Direct Inkjet Printing of Aqueous Inks to Flexible All-solid-state Graphene Hybrid Micro-supercapacitors
}

Bin Li, Nantao Hu*, Yanjie Su, Zhi Yang, Feng Shao, Gang Li, Chaoran Zhang, Yafei Zhang ${ }^{*}$

Key Laboratory of Thin Film and Microfabrication Technology (Ministry of Education), School of Electronics, Information and

Electrical Engineering, Shanghai Jiao Tong University, Dong Chuan Road No.800, Shanghai, 200240, P. R. China

(*E-mail: hunantao@sjtu.edu.cn; E-mail: yfzhang@sjtu.edu.cn;) 
(a)

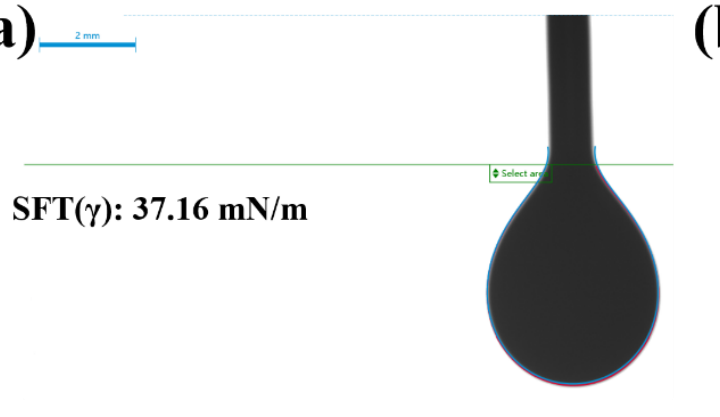

(c)

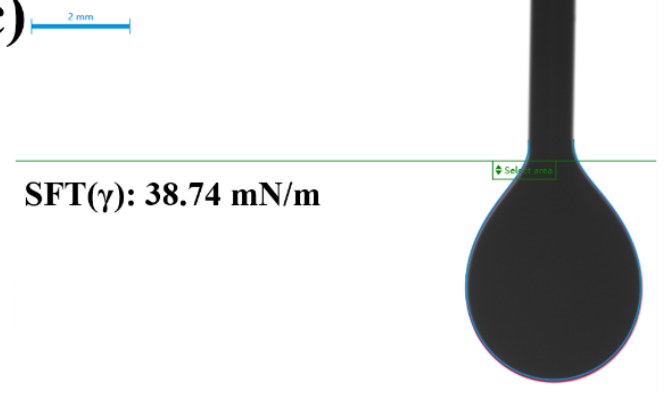

(b)

$\operatorname{SFT}(\gamma): 36.37 \mathrm{mN} / \mathrm{m}$



Figure S1 The surface tension measurement of different inks. (a) GO inks (5 mg/ml); (b) $\left(\mathrm{NH}_{4}\right)_{6} \mathrm{Mo}_{7} \mathrm{O}_{24} \cdot 4 \mathrm{H}_{2} \mathrm{O}$ inks (5 mg/ml); (c) $\mathrm{GO} /\left(\mathrm{NH}_{4}\right)_{6} \mathrm{Mo}_{7} \mathrm{O}_{24} \cdot 4 \mathrm{H}_{2} \mathrm{O}$ composite inks (50:50). 


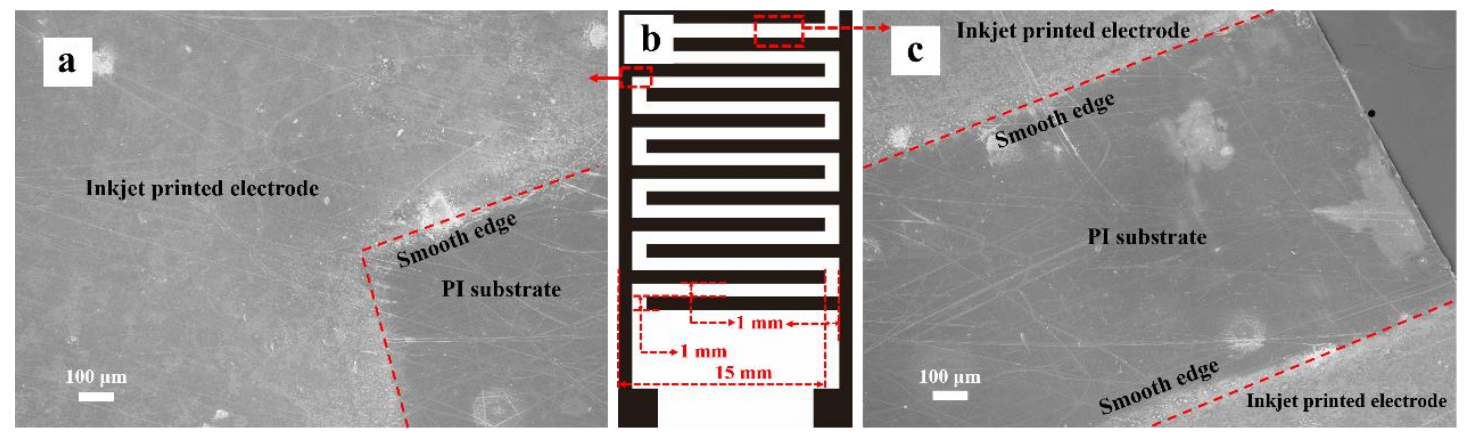

Figure S2 (a) and (c) The SEM images of inkjet printed electrode film on PI substrate. (b) The device geometry measurements of detailed electrode pattern by inkjet printing (the total device area $1.7 * 2.3$ $\left.\mathrm{cm}^{2}=3.9 \mathrm{~cm}^{2}\right)$. 


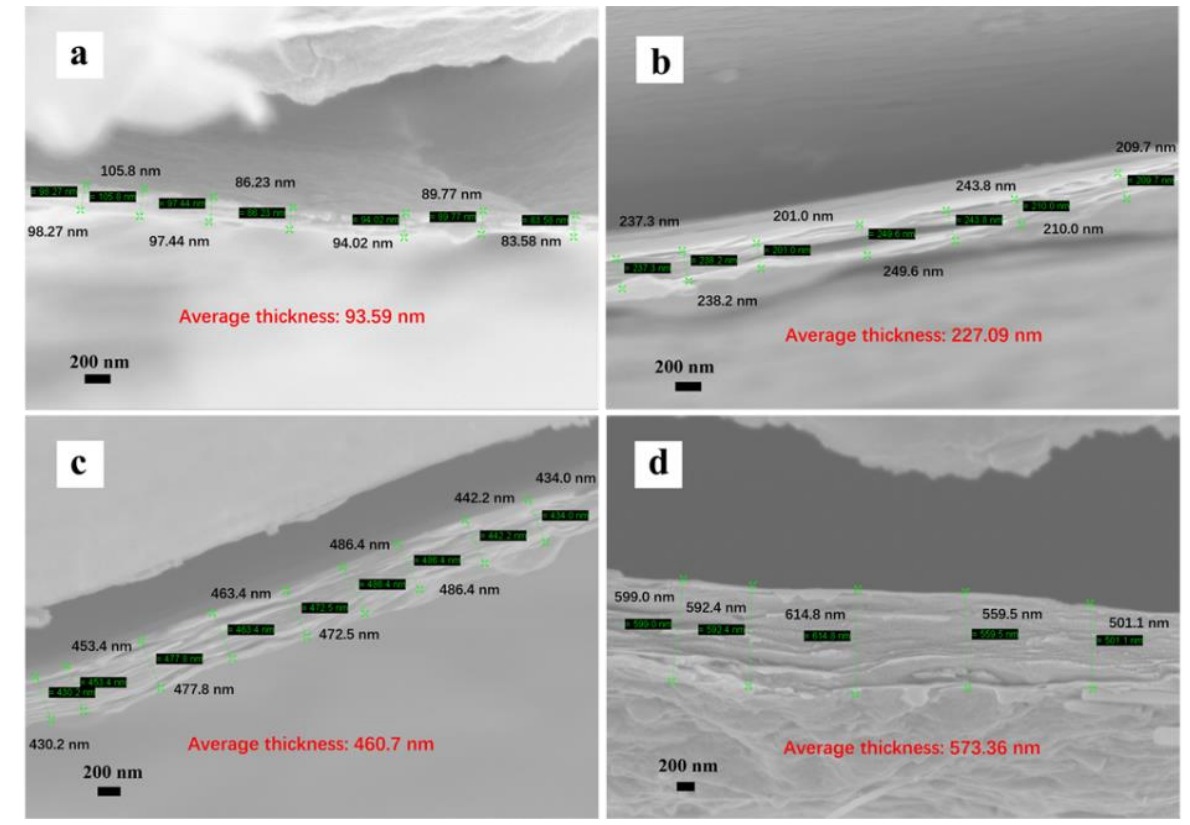

Figure $\mathrm{S} 3$ The thickness of $\mathrm{RGO} / \mathrm{MoO}_{3}$ film for different number of printed layers. (a) five printed layers; (b) ten printed layers; (c) twenty printed layers; (d) thirty printed layers. 




Figure S4 The SEM image of pure $\mathrm{MoO}_{3}$ nanosheets by thermal treatment. (a) SEM image of largearea pure $\mathrm{MoO}_{3}$ nanosheets; (b) High-magnification SEM image of pure $\mathrm{MoO}_{3}$ nanosheets. 


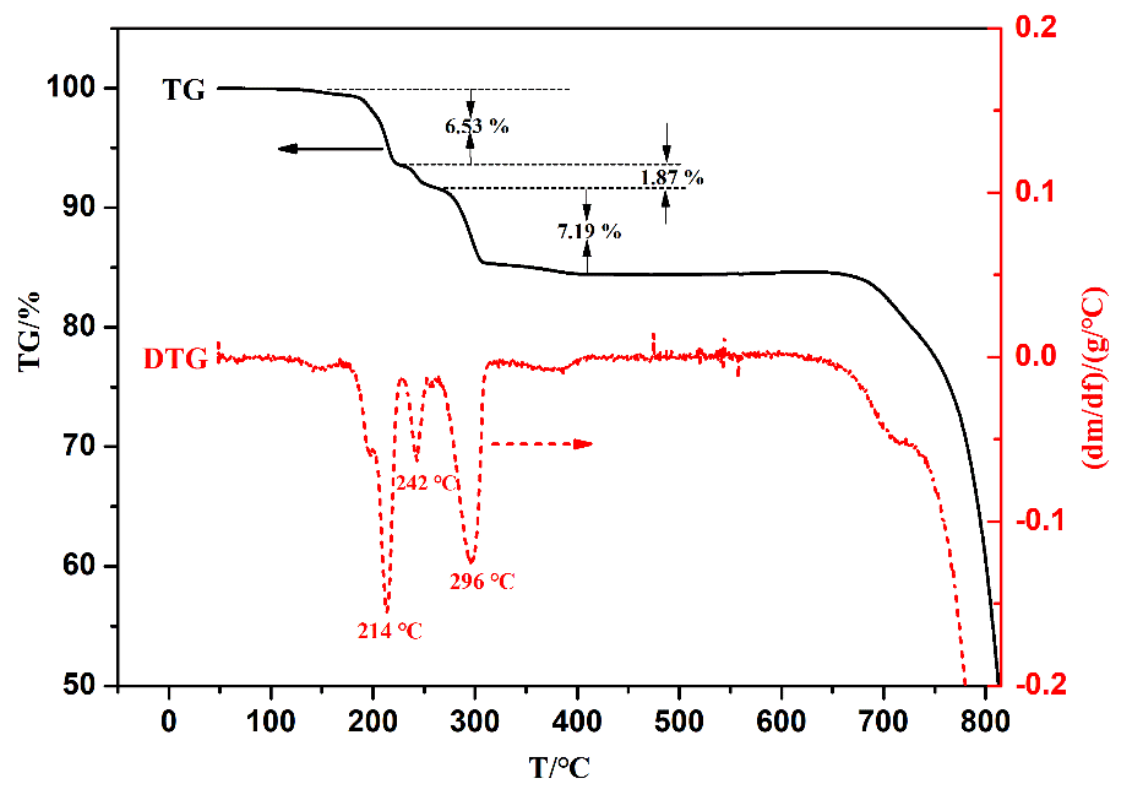

Figure S5 The evolution of weight loss during decomposition of $\left(\mathrm{NH}_{4}\right)_{6} \mathrm{Mo}_{7} \mathrm{O}_{24} \cdot 4 \mathrm{H}_{2} \mathrm{O}$ in air. 


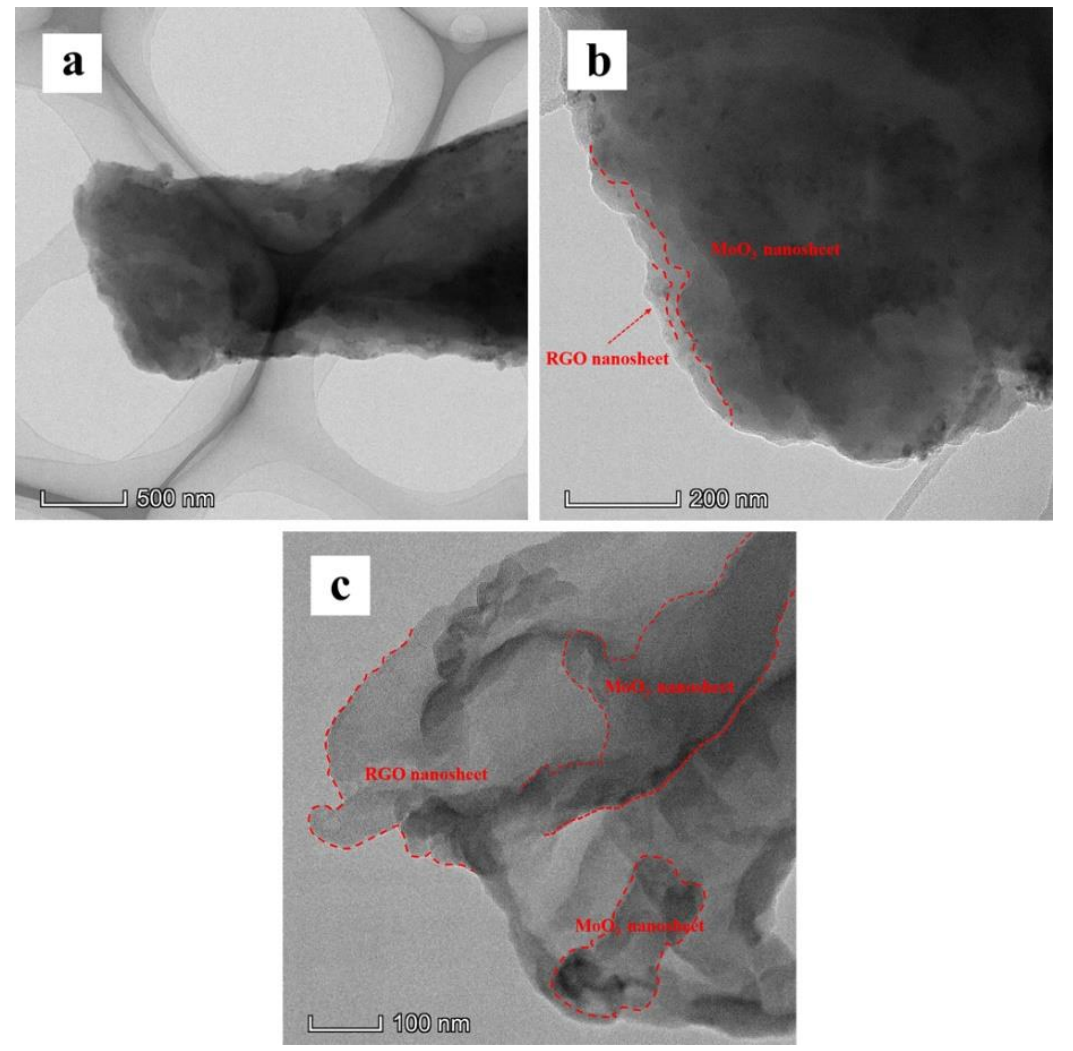

Figure S6 TEM images of $\mathrm{RGO} / \mathrm{MoO}_{3}$ composite nanosheets. 



Figure S7 Cyclic voltammetry of (a) pure $\mathrm{RGO}$ and (b) $\mathrm{RGO} / \mathrm{MoO}_{3}$ at different scan rates from 20 to $400 \mathrm{mV} \mathrm{s}^{-1}$ in $10 \mathrm{mM}\left[\mathrm{Fe}(\mathrm{CN})_{6}\right]^{3-}$ and $0.1 \mathrm{M} \mathrm{KCl}$ solution. 


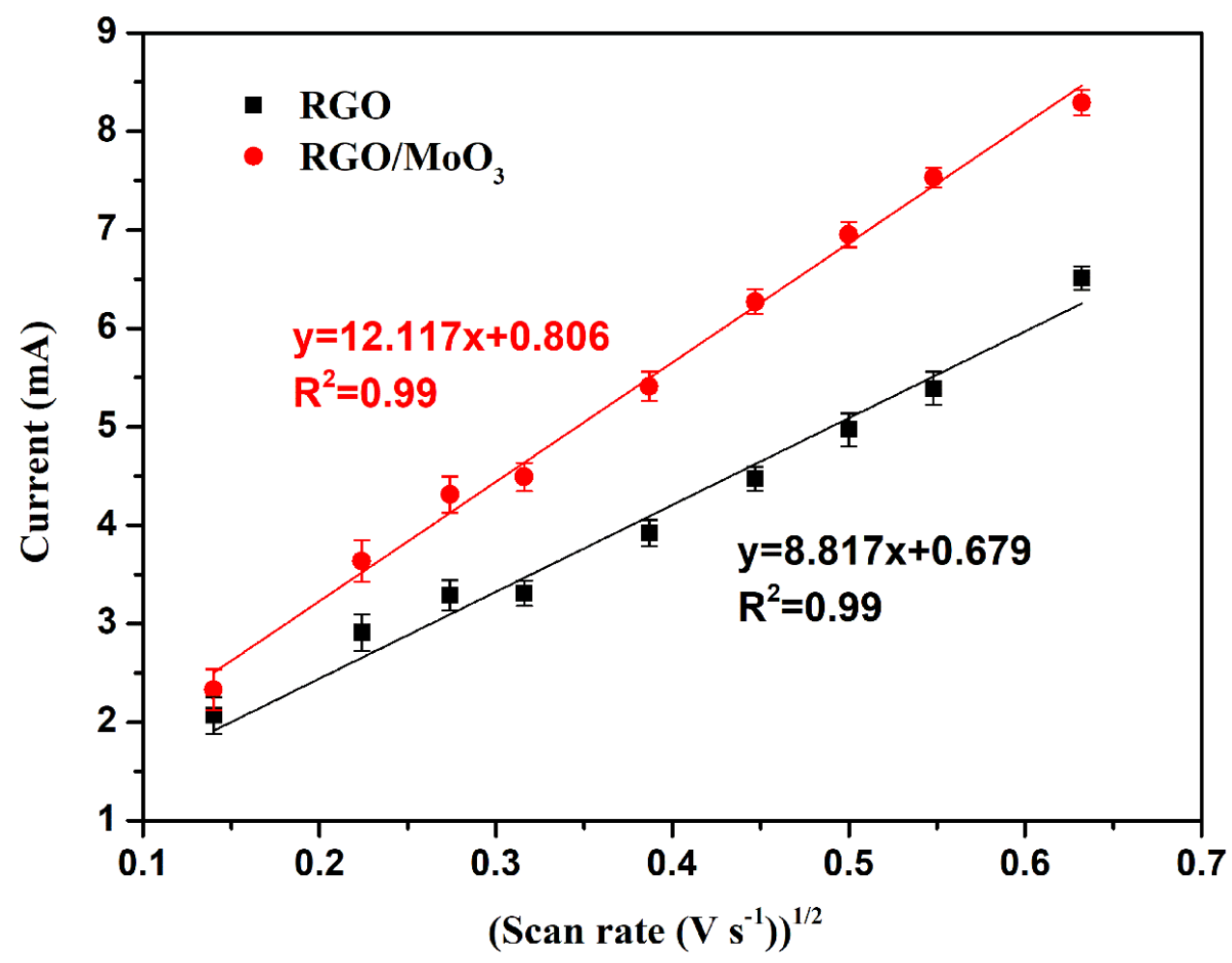

Figure S8 The peak currents as a function of scan rate used for the measurement of the effective surface area. The surface area of pure RGO and $\mathrm{RGO} / \mathrm{MoO}_{3}$ are calculated to be $1.375 \mathrm{~cm}^{2}$ and $1.889 \mathrm{~cm}^{2}$, respectively. 



Figure S9 (a) CV profiles for various layers devices at scan rate of $100 \mathrm{mV} \mathrm{s}^{-1}$. (b) The areal capacitance against printed layers for MSCs (extracted from the CV profiles). 
(a)

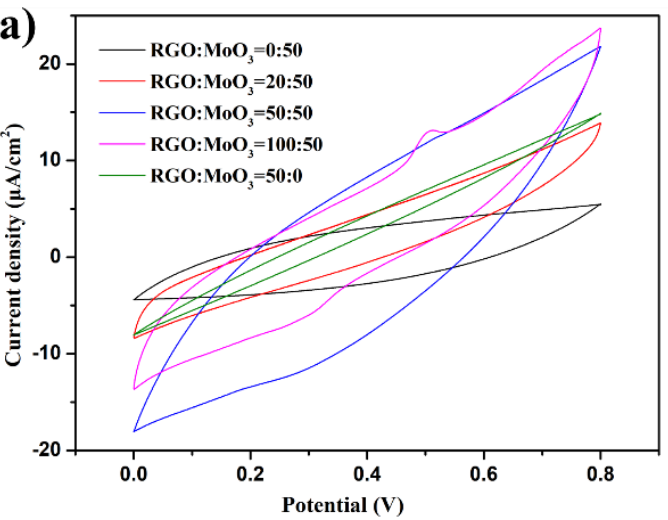



Figure $\mathrm{S} 10$ (a) $\mathrm{CV}$ profiles of MSCs for various proportion of active materials $\mathrm{RGO}$ and $\mathrm{MoO}_{3}$ at scan rate of $100 \mathrm{mV} \mathrm{s}^{-1}$. (b) The areal capacitance against percentage of RGO for MSCs (extracted from the $\mathrm{CV}$ profiles) 
(a)

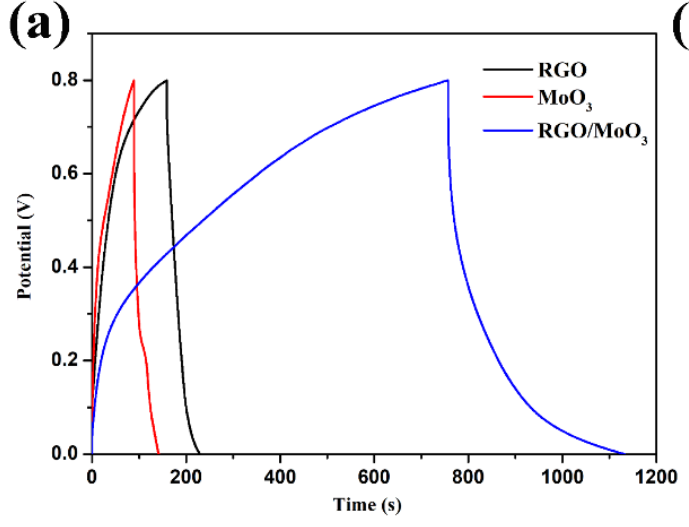

(b)

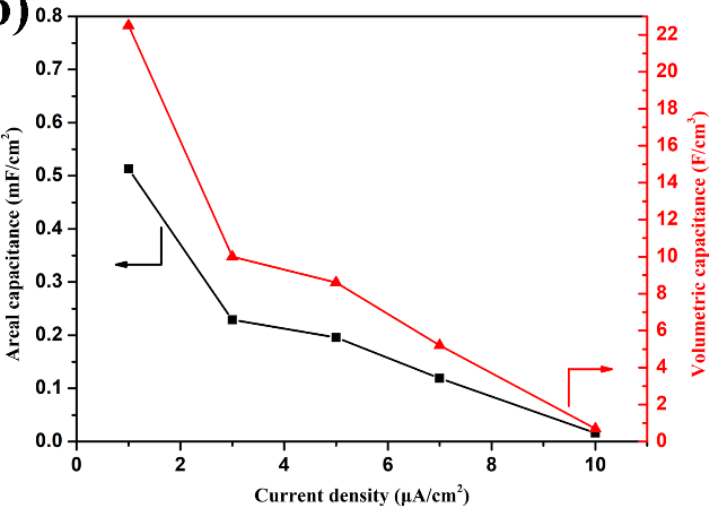

Figure $\mathrm{S} 11$ (a) The GCD curves of inkjet printed $\mathrm{RGO}, \mathrm{MoO}_{3}$ and $\mathrm{RGO} / \mathrm{MoO}_{3} \mathrm{MSCs}$ at a current density of $1 \mu \mathrm{A} \mathrm{cm}^{-2}$. (b) The curve of areal and volumetric capacitance of a printed RGO/MoO $3 \mathrm{MSCs}$ at various current densities. 


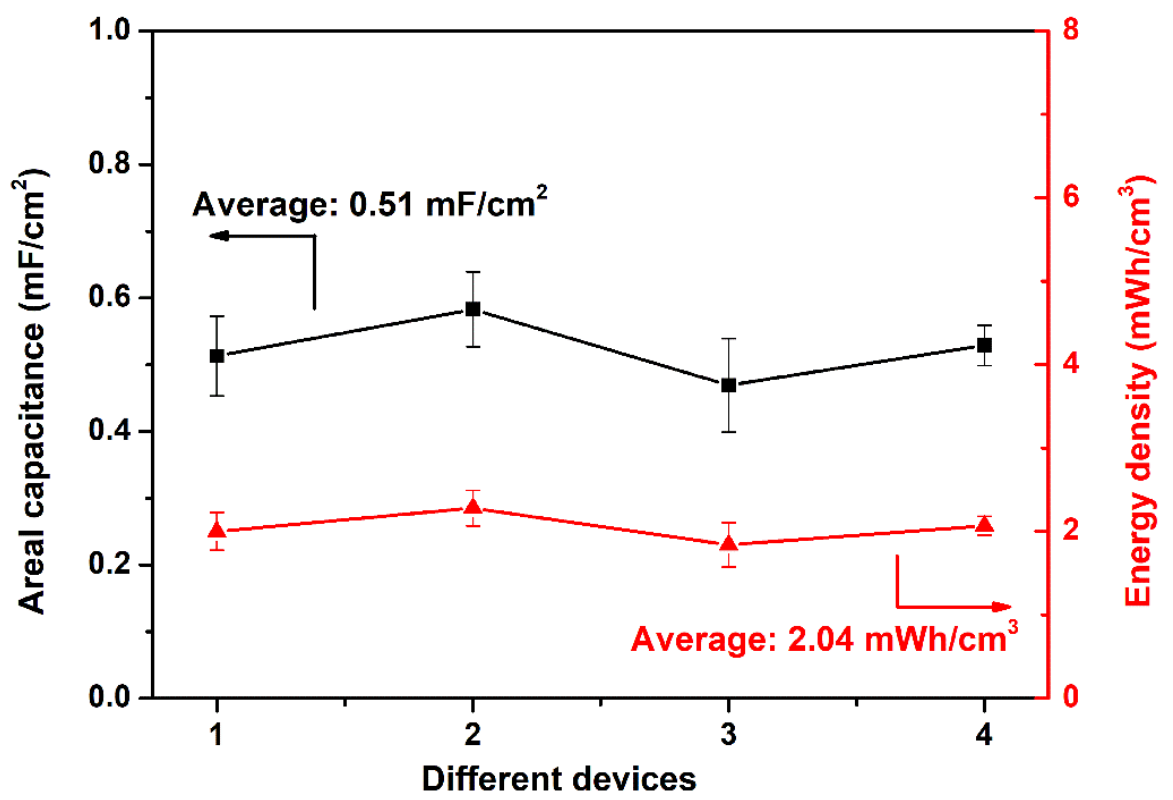

Figure S12 The areal capacitance and energy density for relevant number of devices to assess deviceto-device consistency at a current density of $1 \mu \mathrm{A} \mathrm{cm}^{-2}$. 